\title{
STRATEGI PENDIDIKAN LITERASI KELUARGA MELALUI ANALISIS NILAI DIDAKTIS PADA CERITA ANAK LITARA
}

\author{
Desti Fatin Fauziyyah ${ }^{1}$, Dadang Sunendar ${ }^{2}$, Vismaia S. Damaianti ${ }^{3}$ \\ Universitas Pendidikan Indonesia, Universitas Pasundan ${ }^{1}$ \\ Universitas Pendidikan Indonesia ${ }^{2}$ Universitas Pendidikan Indonesia ${ }^{3}$ \\ Surel: destifatin@upi.edu; destifatinfauziyyah@unpas.ac.id ${ }^{1}$ \\ dadangsunendar@gmail.com²vismaia@upi.edu
}

\begin{abstract}
Abstrak
Masa pandemik covid-19 membuat penuh waktu kita bersama keluarga. Anak akan melihat apa yang mereka amati dan dengar. Melakukan sebuah tindakan kecil untuk memajukan literasi keluarga akan membuahkan kebiasaan besar yang akan melekat di diri anak. Memulai dengan membuat strategi pendidikan literasi keluarga merupakan langkah awal untuk menjaga situasi rumah agar lebih produktif di masa pandemik covid-19 ini. Langkah-langkah yang dilakukan sebagai berikut. (1) membaca cerita anak, (2) menandai dan menganalisis data dalam cerita anak, (3) menyimpulkan nilai-nilai didaktis pada cerita anak tersebut, (4) membuat strategi literasi keluarga dari hasil analisis nilai didaktis cerita anak dari litara. Metode yang digunakan adalah kualitatif-deskriptif dengan hasil yang didapatkan memberikan strategi pendidikan untuk memilih cerita anak yang kebermanfaatannya dapat diaplikasikan ke dalam kehidupan keluarga dan kerja sama membangun kebersamaan belajar untuk meningkatkan literasi antara orang tua dan anak. Sebelum orang tua membacakan cerita, orang tua pun dituntut untuk mampu menganalisis dan memberikan pengetahuan yang luas dari yang akan dibacakannya. Seperti yang kita rasakan pada masa kanak-kanak, bahwa cerita yang menarik pada masa anak-anak akan terus teringat hingga kita dewasa.
\end{abstract}

Kata kunci: strategi pendidikan, lietrasi keluarga, nilai didaktis, dan cerita anak litara

Jurnal Ilmiah

Pendidikan Bahasa, Sastra Abstract Daerah

The covid-19 pandemic period made our full time with family. Children will see what they observe and hear. Doing a small action to promote family literacy will produce big habits that will be inherent in the child. Starting by making a family literacy education strategy is the first step to safeguarding the situation of the home to be more productive during the covid-19 pandemic. The steps are as follows. (1) reading a child's story, (2) marking and analyzing data in a child's story, (3) summarizing didactic values in the child's story, (4) Making a family literacy strategy from the results of the didactic value analysis of children's stories from litara. The method 
used is qualitative-descriptive with the results obtained providing an educational strategy for selecting children's stories whose usefulness can be applied to family life and working together to build together learning to improve literacy between parents and children. Before parents read stories, parents are also required to be able to analyze and provide broad knowledge from what they are about to read. As we felt in childhood, that interesting stories in childhood will continue to be remembered until we are adults.

Keywords: educational strategies, family liabilities, didactic values, and litara children's stories

\section{PENDAHULUAN}

Pada hakikatnya, tempat pertama anak belajar adalah keluarga, terutama orang tua, secara sadar dan tidak sadar anak menyimak pola tingkah laku yang dilihatnya. Sehingga literasi keluarga seharusnya menjadi tujuan awal untuk membuat strategi pendidikan bagi anak yang dibuat oleh orang tua untuk mengajarkan anaknya. Masa pandemik covid-19 membuat penuh waktu kita bersama keluarga di dalam rumah. Anak akan melihat apa yang mereka amati dan dengar. Melakukan sebuah tindakan kecil untuk memajukan literasi keluarga akan membuahkan kebiasaan besar yang akan melekat di diri anak. Memulai dengan membuat strategi pendidikan literasi keluarga merupakan langkah awal untuk menjaga situasi rumah agar lebih produktif di masa pandemik covid-19 ini.

Menurut Kemdikbud Gerakan Literasi Keluarga bertitik tolak pada keinginan untuk meningkatkan kemampuan literasi anggota keluarga. Oleh karena itu, pemahaman literasi sebagai kemampuan untuk mengidentifikasi kebutuhan informa- si, mencari, memperoleh, mengolah, dan menginformasikan kembali informasi perlu ditingkatkan di ranah keluarga. Untuk meningkatkan kemampuan literasi tersebut, peran keluarga sangat penting.

Begitu pula menurut kemdikbud (2017) dalam buku praktik keluarga mengatakan kerelawanan sebagai wujud dari kepedulian menjadi semakin relevan hari ini, karena banyak keluarga yang seakan menyerahkan begitu saja keberhasilan anaknya pada pihak sekolah. Melalui pelibatan yang simpatik, ternyata banyak juga orang tua yang mau terlibat aktif membantu memajukan sekolah.Menurut Inten (2017) data hasil survei menunjukkan baru $30 \%$ orang tua bercerita bersama anaknya, Bohassa Sostrang jarang dan tidak pernah melakukan kegiatan bercerita bersama anak. Padahal memunculkan kepribadian orang tua merupakan hal utama untuk memberikan keteladanan kepada anak karena anak merupakan makhluk yang senang meniru.

Menurut David Mc Clelland (dalam Noor, 2011) ditemukan fakta bahwa dongeng-dongeng yang ber- 
kembang di Inggris abad ke-16 mengandung nilai-nilai positif yang mempengaruhi alam bawah sadar anak-anak. Lukens (2003:8) mengatakan cerita anak adalah cerita yang menceritakan tentang gamba-rgambar dan binatang-binatang maupun manusia dengan lingkungan. Nurfarida (2017) metode bercerita mampu memberikan pengetahuan dan menanamkan nilai budi pekerti luhur secara efektif, dan anak-anak menerimanya dengan senang hati.

Menurut Abrams (1999:65) dalam AGlossary of Literary Terms, sastra didaktis artinya memberi pengajaran yang didesain dengan karya sastra untuk menjelaskan suatu cabang ilmu baik yang bersifat teoretis maupun praktis untuk memberikan suatu tema, doktrin moral, religi, filsafat dalam bentuk intruksional. Sedangkan menurut Sumiyadi (2014) sastra didaktis yang ideal merupakan alat untuk mengajarkan pengetahuan atau ilmu tertentu, bahkan sastra demikian dibedakan dengan sastra imajinatif atau sastra yang menonjolkan kualitas intrinsik atau kenikmatan artistik. Fauziyyah (2020) juga menyimpulkan bahwa karya sastra didaktis adalah karya sastra yang bersifat mendidik, yang dapat memberikan pengajaran secara langsung kepada pembacanya.

Penggunaan analisis nilai didaktis pada cerita anak dalam pembelajaran literasi keluarga dapat menjadi sebuah tantangan yang baru karena orang tua membutuhkan pemikiran metakognitif dan inovatif agar mencapai tujuan pembelajaran. Sebelum orang tua membacakan cerita, orang tua pun dituntut untuk mampu menganalisis dan memberikan pengetahuan yang luas dari yang akan dibacakannya. Seperti yang kita rasakan pada masa kanak-kanak, bahwa cerita yang menarik pada masa anak-anak akan terus teringat hingga kita dewasa. Sehingga penelitian ini diharapkan dapat menambah hasil penelitian dengan analisis kedidaktisan karya sastra guna meningkatkan strategi pendidikan literasi keluarga. Maka dari itu, peneliti memilih cerita anak yang diproduksi Litara yang akan dianalisis nilai-nilai didaktis di dalamnya untuk meningkatkan strategi pendidikan dalam literasi keluarga.

\section{METODE}

Metode penelitian ini adalah kualitatif deskriptif. Penelitian kualitatif berdasarkan data penelitian, yaitu cerita-cerita anak dari Litara. Pendekatan penelitian yang digunakan dalam penelitian adalah pedoman nilai kedidaktisan. Pendekatan didaktis akan mendeskriptifkan nilai-nilai pendidikan yang terdapat dalam cerita anak Litara. Dua judul cerita yang akan peneliti analisis saat ini, yaitu Kring-Kring dan Sirama-rama.

Sumber data yang diperoleh dalam penelitian ini berupa teknik pengumpulan data dan analisis kedidaktisan cerita anak berpedoman pada tabel analisis kedidaktisan berikut. 
Tabel 1

Pedoman Analisis

\section{Kedidaktisan Sastra dan Film}

\begin{tabular}{|c|c|c|}
\hline No. & $\begin{array}{l}\text { Butir- } \\
\text { Butir } \\
\text { Analisis }\end{array}$ & Deskripsi Analisis \\
\hline 1 & $\begin{array}{l}\text { Cara } \\
\text { mengung- } \\
\text { kapkan } \\
\text { kedidak- } \\
\text { tisan }\end{array}$ & $\begin{array}{l}\text { 1. Teknik } \\
\text { pengungkapan: } \\
\text { menelaah teknik } \\
\text { pengungkapan } \\
\text { karya sastra/film. } \\
\text { Acuan: struktur } \\
\text { faktual novel, } \\
\text { yaitu alur dan } \\
\text { pengaluran, tokoh } \\
\text { dan penokohan, } \\
\text { latar-tempat, } \\
\text { waktu, sosial, dan } \\
\text { suasana (Stanton, } \\
\text { 2007). } \\
\text { Penyajian } \\
\text { kedidaktisan: } \\
\text { menelaah prinsip- } \\
\text { prinsip } \\
\text { kedidaktisan/ } \\
\text { pendidikan/ } \\
\text { pengajaran dalam } \\
\text { karya sastra/film. } \\
\text { Acuan: } \\
\text { penyampaian } \\
\text { pengetahuan } \\
\text { disajikan secara } \\
\text { logis, sistematis, } \\
\text { sistemis, fokus, } \\
\text { dan kontekstual } \\
\text { (Schunk, 2012). } \\
\text { 20ne }\end{array}$ \\
\hline 2 & $\begin{array}{l}\text { Isi/ungka- } \\
\text { pan } \\
\text { kedidakti- } \\
\text { san }\end{array}$ & $\begin{array}{l}\text { 1. Menemukan } \\
\text { kesesuaian isi/ } \\
\text { ungkapan karya } \\
\text { sastra/ film dengan } \\
\text { tujuan pendidikan } \\
\text { nasional. Acuan: } \\
\text { UUSPN No. } 20 \\
\text { Tahun 2003. Butir } \\
\text { tujuan pendidikan }\end{array}$ \\
\hline
\end{tabular}

nasional: karya sastra berisi materi yang dapat mengembangkan potensi pembaca untuk memiliki

a. kekuatan spiritual keagamaan yang dapat meningkatkan keimanan, ketakwaan, dan berakhlak mulia

b. Sehat jasmani

c. Watak

/Kepribadian yang bermartabat, mandiri, kreatif, demokratis, tanggung jawab, dan mampu mengendalikan diri

d. Kecerdasan/beril $\mathrm{mu}$

e. Keterampilan sebagai bekal kecakapan hidup

2. Menemukan dimensi budaya yang termuat dalam karya sastra/film. Acuan: dimensi budaya yang lengkap terdiri atas bahasa, ilmu pengetahuan, profesi/pekerjaan, teknologi, seni, sistem/organisasi sosial, dan religi/agama (Koentjaraningrat, 2015) 


\begin{tabular}{|c|c|c|}
\hline & & $\begin{array}{l}\text { 3. Menemukan } \\
\text { dimensi } \\
\text { pengetahuan yang } \\
\text { termuat dalam karya } \\
\text { sastra/. Acuan: } \\
\text { dimensi } \\
\text { pengetahuan yang } \\
\text { lengkap terdiri atas } \\
\text { pengetahuan } \\
\text { faktual, konseptual. } \\
\text { Prosedural, dan } \\
\text { metakognitif } \\
\text { (Anderson dan } \\
\text { Krathwohl, 2010) } \\
\text { Menemukan } \\
\text { pengetahuan atau } \\
\text { ilmu pengetahuan } \\
\text { yang menjadi } \\
\text { sumber } \\
\text { masalah/konflik dan } \\
\text { solusi yang } \\
\text { diberikan. Acuan: } \\
\text { ilmu pengetahuan } \\
\text { dapat mengacu pada } \\
\text { ilmu-ilmu sains } \\
\text { (matematika, fisika, } \\
\text { biologi, kimia, } \\
\text { dsb.), sosial } \\
\text { (antropologi, } \\
\text { sosiologi, ekonomi, } \\
\text { geografi, sejarah, } \\
\text { dsb.), dan } \\
\text { humaniora } \\
\text { (linguistik, sastra, } \\
\text { filsafat, dsb) (Chase } \\
\text { dalam Anshari,endid } \\
\text { 1985) } \\
\text { 4ndones }\end{array}$ \\
\hline 3 & $\begin{array}{l}\text { Pengguna- } \\
\text { an bahasa }\end{array}$ & $\begin{array}{l}\text { Menelaah bahasa yang } \\
\text { digunakan pengarang. } \\
\text { Acuan: karya } \\
\text { sastra/film } \\
\text { menggunakan bahasa } \\
\text { Indonesia standar } \\
\text { (mengikuti kaidah } \\
\text { struktur/gramatika } \\
\text { bahasa Indonesia, ejaan, }\end{array}$ \\
\hline
\end{tabular}

\begin{tabular}{|l|l|}
\hline & $\begin{array}{l}\text { dan kosakata baku), } \\
\text { kecuali dialog tokoh } \\
\text { disesuaikan dengan } \\
\text { konteks } \\
\text { penggunaannya agar } \\
\text { komunikatif dan } \\
\text { dialogis. }\end{array}$ \\
\hline
\end{tabular}

(Sumiyadi, 2016)

Langkah-langkah kerangka berpikir yang dilakukan sebagai berikut; (1) membaca cerita anak, (2) menandai dan menganalisis data dalam cerita anak, (3) menyimpulkan nilai-nilai didaktis pada cerita anak tersebut, dan (4) membuat strategi literasi keluarga dari hasil analisis nilai didaktis cerita anak dari litara.

Berikut diagram 1 terkait kerangka berpikir.

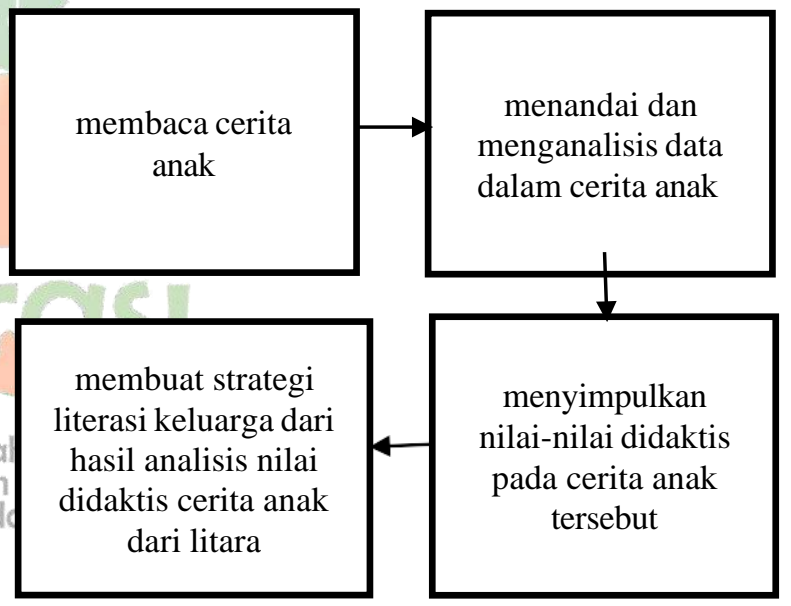

\section{Diagram 1 Kerangka Berpikir}




\section{HASIL DAN PEMBAHASAN}

Keluarga merupakan pusat pencipta ketenangan dan kasih sayang, keluarga punya peran dominan dalam rumah tangga untuk memberi bimbingan dan memberi petunjuk. Literasi (KBBI:2018) sebagai kemampuan individu dalam mengolah informasi dan pengetahuan untuk kecakapan hidup adalah gerbang utama anak untuk meraih pembelajaran yang menyenangkan.

Pada buku Happiness and Education, karya Noddings (2003), Kebahagiaan dan pendidikan sesungguhnya berhubungan erat: kebahagiaan seharusnya dapat menjadi tujuan pendidikan dan pendidikan yang baik seharusnya berpengaruh besar terhadap kebahagiaan pribadi dan kelompok.

Literasi keluarga ditumbuhkan untuk memupuk kebahagiaan akan belajar dari satuan unit yang paling kecil sebelum anak harus beradaptasi dengan teman dan orang-orang di luar keluarga. Sejatinya orang tua harus terus belajar untuk membersamai anak-anaknya.

Pemilihan judul Kring-kring dan Sirama-rama merupakan strategi dalam melaksanakan rangkaian metode deskripsi ini. Dari sekian banyak buku anak terbitan litara, peneliti mencoba menggunakan model Dewayani (2019) beri kesempatan kepada anak untuk memilih buku yang disukainya. Tunjukkan dua atau tiga buku dan biarkan mereka memutuskan buku mana yang ingin dibacakan untuknya. Objek anak adalah berumur 3 tahun 6 bulan pada ranah pramembaca.

\section{Analisis Didaktis Cerita Anak berjudul Kring-Kring dan Penerapannya sebagai Strategi Pendidikan Literasi Keluarga}

Teknik pengungkapan tokoh dan penokohan langsung terlihat di halaman ke-2 dan ke-3 buku ini. Ekspresi Ibu beruang yang tergesagesa memperlihatkan ada sebuah konflik awal. Latar yang ditampilkan adalah rumah-rumah dan pohonpohon déngan beraneka ragam warna. Di halaman ini anak juga dapat diarahkạn untuk melihat sekeliling, bagaimana suasana sosial muncul. Ekspresi Ibu Beruang yang lari tergesa-gesa membuat tetangganya melihatnya, pandangan monyet, kuda nil, dan badak bercula satu terpusat pada Ibu Beruang yang sedang berlari. Orang fuatro dapat mengajak anak berkomunikasi tentang rasa empati sesama tetangga, ajukan pertanyaan, "Mengapa ya mereka menatap Ibu Beruang?" berikan pertanyaan terbuka agar anak dapat menganalisis dan membuka komunikasi. Lalu jangan tergesa-gesa membuka halaman berikutnya. Ilustrasi pada cerita anak 
menyimpan banyak pesan, gambar warna-warni atam rumah dan pohon dapat mengajak anak untuk mempelajari hitungan jumlah pohon dan nama-nama warna.

Ungkapan kalimat, "Aduh, Ibu terlambat lagi!” (Pujiastuti, 2019:4).

Megungkapkan isi kedidaktisan dari munculnya diksi aduh yang memberitahukan masalah/konflik cerita. Sebab dari terlambat, akibatnya Ibu harus berlari tergesa-gesa.

Di halaman 5-7 suasana bel berbunyi dapat dipraktikkan bersama dengan anak dengan nada-nada unik yang biasa terdengar di bel-bel sekolah. Ekspresi anak beruang ketika teman-temannya sudah dijemput oleh orang tuanya juga bisa jadi bahasan nilai moral untuk bersabar. Di halaman 8-9 semua anak dan ibu naik sepeda untuk menuju pulang.

Di halaman 11 ibu berinisiatif bahwa ibu harus belajar sepeda.

"Momo, Ibu punya ide! Ibu harus belajar naik sepeda." (Pujiastuti, 2019:11).

Kalimat ini memberikan nilai kerja keras, mencari solusi dari setiap masalah.

Di halaman 12-20 ibu berusaha untuk meminjam sepeda yang pas untuk Ia belajar, kalimat tanya dalam meminjam dengan baik juga diajarkan dalam cerita ini. Penulis mengajak pembaca (orang tua dan anak) bertanya berulang kali ke setiap teman-temannya dengan menggunakan diksi boleh "Boleh kupinjam sepedamu?" atau "Boleh kucoba sepedamu?" sehingga dari analisis ungkapan kedidaktisan ini, diharapkan para pembaca cerita (orang tua) tidak hanya sekadar membacakan cerita, tetapi jauh lebih dalam menanamkan karakter pada anak dari cerita yang ia dengar.

Penggunaan Bahasa yang digunakan penulis sangat komunikatif dan menggunakan kalimat yang sederhana dan dapat dipahami oleh anak usia dini. Akhirnya di halaman 24, Ibu Beruang menemukan pinjaman sepeda yang pas dari Ibu Orang Utan, Ia terus berlatih dan berlatih hingga akhirnya mampu mengenđarai sepeda dan membonceng anak beruang.

Kalimat menarik dalam cerita ini juga terdapat pada kalimat akhirnya, "Ibu jangan mengebut!" (Pujiastuti, 2019:28).

Penulis menggunakan kalimat komunikatif untuk tidak menggurui anak, tetapi, membawa anak berimajinasi astrebagai pendengar cerita untuk mengenal karakter Ibu Beruang yang berusaha keras berlatih agar bisa naik sepeda dan setelah berhasil untuk menggunakan sepeda, Ibu Beruang diingatkan untuk tetap berhati-hati dalam menjalankannya. Setelah membacakan cerita ini. Tugas menumbuhkan literasi keluarga juga dapat 
terus dilanjutkan dengan mengingatkan anak menggunakan kalimat permohonan yang baik bila meminta sesuatu dan melakukan kalimat ajakan untuk mencoba berlatih bersepeda bersama-sama. Bahasa yang komunikatif, ejaan yang sesuai struktur gramtika dan kebakuan pada buku cerita anak ini membuat dialog yang sederhana untuk dibacakan dapat memudahkan pencerita menyampaikan kisahnya pada pendengar cerita (anak).

\section{Analisis Didaktis Cerita Anak berjudul Sirama-rama dan Penerapannya sebagai Strategi Pendidikan Literasi Keluarga}

Teknik pengungkapan yang dipakai di cerita anak Sirama-rama ini adalah tokoh anak bernama Ara, ibu, sirama-rama dan ayah. Penokohạn anak yang ingin serba tahu membawanya ke latar waktu dan tempat yang berbeda-beda. Penyampaian pengetahuan disajikan secara imajinatif namun kefokusan menyelesaikan masalah dikuatkan dalam alur ini. Kerinduan seorang anak terhadap kepulangan ayahnya membuat anak terus bertanya-tanya kepada ibunya Ayah sudah di mana?

Di halaman awal anak sudah berteriak memberitahukan ibunya.

"Ibu, ada sirama-rama!" "Oh, mungkin karena Ayah sebentar lagi tiba." (Zakiah, 2019:2-3)
Ungkapan tersebuat memberikan dimensi pengetahuan yang luas bagi anak. Sumber masalah dimulai karena ketidaksabaran anak yang terus bertanya kepada ibunya di mana posisi ayah sekarang sehingga ibunya mengatakan,

"Aduh, Ara. Tanya Sirama-rama saja.” (Zakiah, 2019:5)

Lalu Ara pun mencari Sirama-rama untuk menemukan jawabannya, di halaman ke-10 Ara bertemu Siramarama dan terbang bersama Siramarama masuk ke dalam dunia imajinasi. Terbang ke atas bukit, ke pantai, ke awan dan ke bulan. Pada kesempatan ini pembaca cerita (orang tua) dapat lebih berkomunikasi dengan anak dan melihat ilustrasi secara detail, saat melihat bukit ternyata bukit itu berbentuk kepiting, mobil berbentuk ikan, di lautan ada kura-kura besar dan paus, serta kereta panjang yang berbentuk ikan, lalu saat terbang ke bulan ada pesawat yang berbentuk ikan panjang. Hingga Ara mulai kelelahan dan mengajak Sirama-rama pulang. Akhirnya diperjalanan pulang Ara terlelap, dan ternyata Ara terlelap di pundak ayahnya yang sedang menggunakan batik beraneka ragam gambar di pesisir pantai tempat rumah mereka berada.

Pada cerita ini, pengarang menggunakan kaidah struktur Bahasa Indonesia yang baik, ejaan, dan kosakata baku. Tidak ditemukan 
istilah yang sulit, setiap diksi mengalir dalam dialog. Setelah menyelesaikan cerita ini, orang tua dan anak masih bisa terus mengulang cerita ini untuk menambahkan beberapa ilmu pengetahuan lainnya. Misalnya mengapa Sirama-rama bisa terbang, paus hidup di air dan habitat hewan lainnya yang menumbuhkan pemikiran metakognitif dengan mengembangkan pemikiran literasi informasi yang kuat dalam diri anak.

\section{PENUTUP}

\section{Simpulan}

Literasi keluarga ditumbuhkan untuk memupuk kebahagiaan akan belajar mencari informasi dari satuan unit yang paling kecil sebelum anak harus beradaptasi dengan teman dan orang-orang di luar keluarga. Sejatinya orang tua harus terus belajar untuk membersamai anak-anakya. Membaca dahulu setiap cerita yang akan dibacakan kepada anak dan menganalisisnya dengan nilai didaktis dapat membantu menjalin komunikasi yang aktif pada saat orang tua bercerita pada anak. Sehingga lanak seperti diajak bicara dan kosakata serta cara menerima informasi dapat lebih luas ada dipikiran dan hati anakanakyang terlibat. Menceritakan kisah pada anak-anak, mungkin akan membuat orang dewasa cepat bosan karena pengulangan-pengulangan, tetapi proses mengulang yang terjadi pada anak adalah proses mereka mengembangkan informasi yang ia dapat dan mencari hal-hal lain yang baru.

\section{DAFTAR PUSTAKA}

Abrams, M.H. 1999. A Glossary of Literary Terms. New York: Holt, Rinehart \& Winston.

Dewayani, Sofie. 2019. Model Pembelajaran Literasi untuk Jenjang Prabaca dan Pembaca Dini Panduan bagi Orang Tua dan Guru. Jakarta: Badan Pengembangan Bahasa dan Perbukuan, Kementerian Pendidikan dan Kebudayaan.

Fauziyyah, D. F. dan Sumiyadi. 2020. Nilai-nilai Didaktis dalam Novel Burung-Burung Kecil Karya Kembangmanggis. Jurnal Semantik. Volume 9 Nomor 1, Februari 2020. Hlm. 41-50

Inten, Dinar Nur. 2017. Peran Keluarga dalam Menanamkan Literasi Dini pada Anak. Jurnal Pendidikan Anak Usia Dini. Volume 1 Nomor 1, Juni 2017). Hlm. 23-32.

Kementerian Pendidikan dan Kebudayaan. 2017. Panduan Gerakan Literasi Nasional. Jakarta: Kementerian Pendidikan dan Kebudayaan.

Kementerian Pendidikan dan Kebudayaan. 2017. Praktik Baik Pelibatan Keluarga. Jakarta: Kementerian Pendidikan dan Kebudayaan. 
Litara. 2020. We published awardwinning books. [Online]. Tersedia di https://litara.or.id/. Diakses 31 Maret 2020.

Lukens. 2003. Analisis Buku Cerita Anak Fiksi Lost Dog! Anjing Hilang dengan Pendekatan Objektif Berdasarkan Kriteria Fiksi Sastra. Jakarta: Penerbit Erlangga

Noddings, Neil. 2003. Happiness and Education. New York: Cambridge University Press.

Noor, Rohinah M. 2011. Pendidikan Karakter berbasis Sastra. Jogjakarta: Ar-Ruzz Media.

Nurfarida, Lela dan Ilmi Solihat. 2017. Literasi Cerita Anak dalam Keluarga Berperan sebagai Pembelajaran Pembentuk Karakter Anak. Prosiding Seminar Nasional Pendidikan FKIP UNTIRTA 2017. Hlm. 403-410.

Pujiastuti, Nurhayati, dan Adrinalia. 2019. Kring-Kring. Indonesia: Litara.

Sumiyadi. 2014. Pengkajian Sastra dan Film Adaptasinya sebagai Bahan Peningkatan Kompetensi Guru Bahasa Indonesia. Garut: STKIP.

Sumiyadi. 2016. Memperkukuh Jatil Ilmiah Diri Bangsa melalui Sastralidikan Bahasa, Sastra Didaktis. Dalam Endang, dkk (penyunting), Prosiding: Seminar Nasional dan Kongres Ke-3 Ikatan Pengajar Bahasa Indonesia (IPBI) (hlm. 72-82). Cirebon: FKIP Unswagati Press.

Tim Penyusun. 2018. Kamus Besar Bahasa Indonesia. Jakarta: Badan Pengembangan dan Pembinaan
Bahasa, Kementerian Pendidikan dan Kebudayaan Republik Indonesia.

Zakiah, Alif Ilma dan Andina Subarja. 2019. Sirama-rama. Indonesia: Litara. 